\title{
Removal of Heavy Metals (Lead, Cadmium and Iron) from Low-Grade Nanoscale Zinc Oxide using Ammonium Carbonate Solution as a Leaching Agent
}

\author{
MUHAMMAD Yasir Khan ${ }^{1, a,{ }^{*}}$, ALI Dad Chandio ${ }^{2, b}$, MUHAMMAD Sohail ${ }^{2}$, \\ SYED Zeeshan Abbas ${ }^{3}$, RAO Shakeel Ahmed ${ }^{4}$, SHAHID Bhutto ${ }^{5}$ \\ and SYED Junaid Mehmood ${ }^{5}$ \\ ${ }^{1}$ Department of Chemical Engineering, University of Karachi, Karachi, 75270, Pakistan \\ ${ }^{2}$ Department of Materials \& Metallurgical Engineering, NED University of Engineering and \\ Technology, Karachi, 75270, Pakistan \\ ${ }^{3}$ Department of Physics, University of Karachi, Karachi, Pakistan \\ ${ }^{4}$ Nordtec International, Karachi, Pakistan \\ ${ }^{5}$ Pakistan Council of Scientific \& Industrial Research (PCSIR) Laboratories, Karachi, Pakistan \\ a*myasir@uok.edu.pk, balidad_24@hotmail.com
}

Keywords: ZnO; Heavy Metals; Purification; Leaching Agent

\begin{abstract}
This study investigated purification and refining methods for producing a nanometer size zinc oxide $(\mathrm{ZnO})$ from low-grade $\mathrm{ZnO}$ commercial powder using low cost ammonium carbonate solution as a leaching agent. The atomic absorption spectroscopy results show that the concentration of lead, cadmium and iron can be significantly reduced by ammonium carbonate leaching and washing. X-ray diffraction and scanning electron microscope results show that structural properties can improve the degree of the preferential c-axis orientation, grain size, and surface morphology of $\mathrm{ZnO}$ by solvent evaporation. All physical and chemical results are of particular significance for the preparation of purified $\mathrm{ZnO}$ for device fabrication in photovoltaic industry, functional $\mathrm{ZnO}$ coatings, and polymer nanocomposite applications.
\end{abstract}

\section{Introduction}

Today zinc oxide is highly demanded and an active material as key ingredient in several mineral sunscreens, vitamin supplements, diaper rash creams and acne treatments sold in drug stores [1]. Heavy metal impurities such as cadmium, lead and iron in the commercial $\mathrm{ZnO}$ can be considered a problem when used in medicines and other pharmaceutical products. Technologies such as the hydrothermal (HT), pressurized melt growth and gas or vapor transport are traditionally used for high quality zinc oxide production [2]. The most viable method used in industry to produce crystalline bulk $\mathrm{ZnO}$ is HT technique, which is scalable and produces high quality material but it has some possible disadvantages such as the high energy consumption and possible contaminations from the milling media. Other production techniques for crystalline bulk material include vapour phase which can produce high quality and has low impurity concentrations, however it is costly and not simply ascendable [3]. Thus, it is not appropriate for high volume production.

The leach-solvent $\mathrm{p}$-extraction process route is a latest economical method used for the removal of heavy metal impurities from commercial low-grade $\mathrm{ZnO}$ [4]. Low grade $\mathrm{ZnO}$ can also be treated with conventional acidic heap leaching process [5] but ammonia and alkaline leaching is the selective system for purification of $\mathrm{ZnO}$ because of significant operating cost and environmental concern [6].

In this work, the effect of temperature on the leaching of $\mathrm{ZnO}$ from low grade commercial zinc oxide in the ammonium carbonate solution system was studied. The aim of this work was to develop a simple process, which intends to provide economical method to purify $\mathrm{ZnO}$ from lowgrade commercial zinc oxide. 


\section{Experimental Details}

Chemicals. Low grade commercial ZnO (PARS ROOY, Iran) and ammonium carbonate (BDH Laboratory supplies) were used as received without further purification.

Refining of Low Grade Commercial ZnO. Firstly, the raw $\mathrm{ZnO}$ was heat-treated at $600^{\circ} \mathrm{C}$ for two hours in a muffle furnace at an atmospheric pressure in the presence of air. Resulted sample was then cooled in ambient conditions to $200^{\circ} \mathrm{C}$, then to $25^{\circ} \mathrm{C}$ in a desiccator. Secondly, the treated $\mathrm{ZnO}$ was leached in an aqueous ammonium carbonate solution. The leaching solution was prepared by mixing with $30 \mathrm{~g}(2 \mathrm{M})$ ammonium carbonate in $100 \mathrm{~mL} \mathrm{H}_{2} \mathrm{O}$ and heated gradually under vigorous stirring. $15 \mathrm{~g}$ of treated $\mathrm{ZnO}$ was added in the $50 \mathrm{ml}$ of ammonium carbonate solution and stirring was allowed for one hour with occasional addition of gaseous ammonia to control the $\mathrm{pH}$ between 10 and 11 at temperature of $50^{\circ} \mathrm{C}$. The purified $\mathrm{ZnO}$ was separated by centrifugation for 5 minutes and resulting residue was washed with de-ionized $\mathrm{H}_{2} \mathrm{O}$ for 3 times. Finally, Separated $\mathrm{ZnO}$ was dried at $100^{\circ} \mathrm{C}$ for one hour in oven to evaporate water and remove residuals. This is shown in Fig. 1.

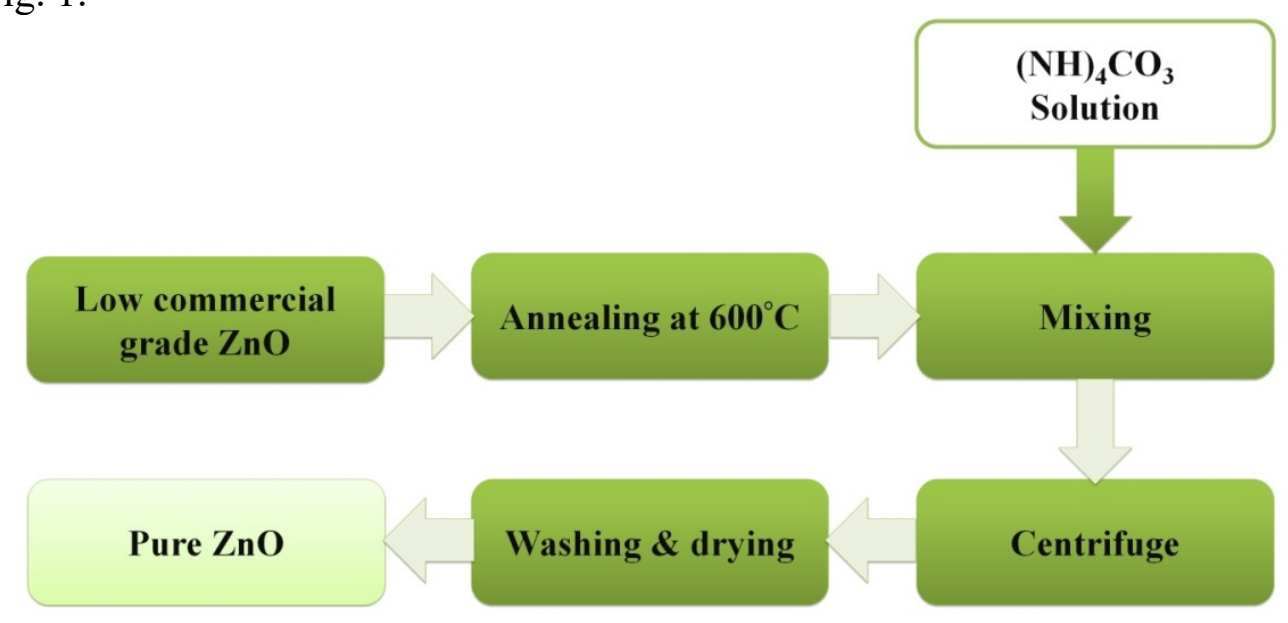

Fig. 1. Schematic illustration of refining process for low grade commercial $\mathrm{ZnO}$.

Characterization. The microstructural investigation was carried out by scanning electron microscopy (SEM, Hitachi S4700) with energy-dispersive X-ray spectroscopy (EDS), Crystallinity of the $\mathrm{ZnO}$ was examined by X-ray diffraction (XRD, Rigaku) with $\mathrm{Cu}-\mathrm{K} \alpha$. An AAS Hitachi atomic absorption spectrophotometer model Z-8000, equipped with a graphite furnace (HGA-400) and an auto-sampler plus high intensity deuterium lamp for background correction was used. The electro- thermal parameters and thermal program are listed in Table 1.

\section{Results and Discussion}

Detailed structural Analysis. Fig. 2 indicates the surface images of SEM analysis for un-treated and treated $\mathrm{ZnO}$ powder samples. The SEM images show an improved morphology of the $\mathrm{ZnO}$ powder after leaching by an ammonium carbonate solution. Fig. 2a and 2a-1 shows the large grains with several voids of the structures surrounded by small grains in un-treated form. On the other hand, the leached sample is found to exhibit good uniformity and well-defined crystal faces with an average size of approximately $200 \sim 300 \mathrm{~nm}$ as shown in Fig. $2 \mathrm{~b}$ and $2 \mathrm{~b}-1$. It can be seen that this leaching process has not only improved crystal quality of the $\mathrm{ZnO}$ powder but also there is no effect on the $\mathrm{ZnO}$ phase. The elemental composition of both un-treated and treated $\mathrm{ZnO}$ powder samples are observed by EDS as shown in Fig. 2a-2 \& b-2. The resulted EDS spectrum confirmed the presence of zinc oxide $(\mathrm{ZnO})$ powder and mostly strong energy peaks are associated for zinc $(\mathrm{Zn})$ atoms and weak energy peak of oxygen $(\mathrm{O})$ atom. In addition, the mass percentage of zinc and oxygen values is tabulated along with impurities present in both samples in the Table 2 .

The crystallinity and purity of un-treated and treated $\mathrm{ZnO}$ powders were further characterized by XRD analysis and shown in Fig. 3. Both samples exhibited the highly crystalline and stable well indexed hexagonal wurtzite ZnO (JCPDS card No. 36-1451) phase [7, 8]. However, it was observed 
that without treatment of the raw commercial $\mathrm{ZnO}$ powders, the additional impurity peaks of $\mathrm{Pb}, \mathrm{Cd}$ and Fe, Fig. 3a, were seen while $\mathrm{ZnO}$ powders treated in ammonium carbonate solution, Fig. 3b, display a sharp and intense peak indicating a fine crystalline wurtzite structure without any impurities. Generally, leaching of low quality $\mathrm{ZnO}$ in Ammonium an ammonium solution system follows the kinetic law of shirking-core model and concentration of leaching agent causing the removal of impurities from $\mathrm{ZnO}$ [9].

Table 1. Measurement conditions for atomic absorption spectroscopy (AAS).

\begin{tabular}{|l|c|c|c|}
\hline \multicolumn{1}{|c|}{ Conditions } & Pb & Cd & Fe \\
\hline Lamp current $[\mathrm{mA}]$ & 7.5 & 7.5 & 10 \\
\hline Wave length $[\mathrm{nm}]$ & 283.3 & 228.8 & 240.3 \\
\hline Slit width $[\mathrm{nm}]$ & 1.3 & 1.3 & 0.2 \\
\hline Cuvette & Tube & Tube & - \\
\hline Atomizer & - & - & STD burner \\
\hline Carrier gas argon $[\mathrm{ml} / \mathrm{min}]$ & 200 & 200 & - \\
\hline Sample volume $[\mu \mathrm{L}]$ & 20 & 20 & - \\
\hline Burner height $[\mathrm{mm}]$ & - & - & 7.5 \\
\hline Acetylene pressure $\left[\mathrm{kg} / \mathrm{cm}^{2}\right]$ & - & - & 0.3 \\
\hline
\end{tabular}
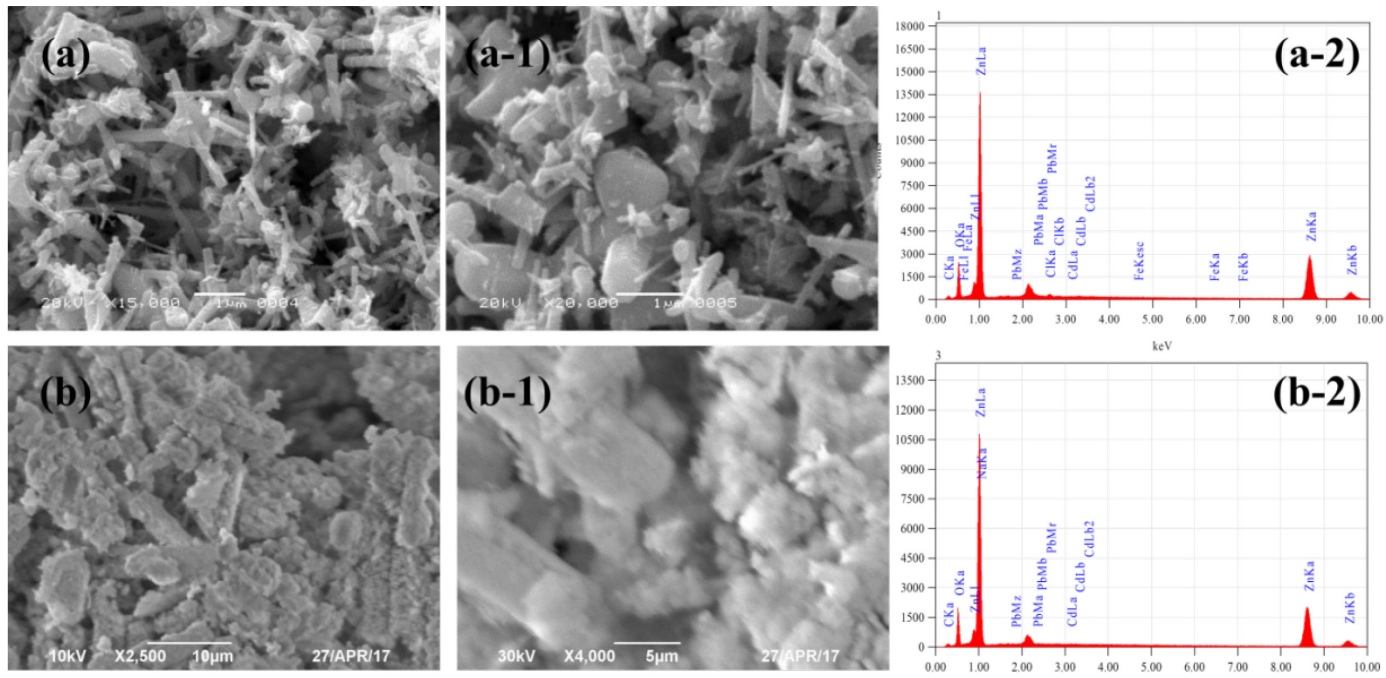

Fig. 2. SEM images and EDS analysis of Un-treated $\mathrm{ZnO}$ (a), (a-1), (a-2) and treated $\mathrm{ZnO}$ (b), (b-1), (b-2).

Table 2. Chemical composition of un-treated and treated $\mathrm{ZnO}$ observed by EDS Analysis.

\begin{tabular}{|l|c|c|c|c|c|c|c|c|}
\hline \multicolumn{1}{|c|}{ Elements } & $\mathbf{C}$ & $\mathbf{O}$ & $\mathbf{C l}$ & $\mathbf{Z n}$ & $\mathbf{P b}$ & $\mathbf{C d}$ & $\mathbf{F e}$ & Total \\
\hline Un-treated ZnO (wt.\%) & 5.24 & 17.66 & 4.34 & 71.74 & 0.64 & 0.15 & 0.22 & 100 \\
\hline Treated ZnO (wt.\%) & 4.99 & 21.08 & 0.80 & 72.86 & 0.14 & 0.09 & 0.02 & 100 \\
\hline
\end{tabular}



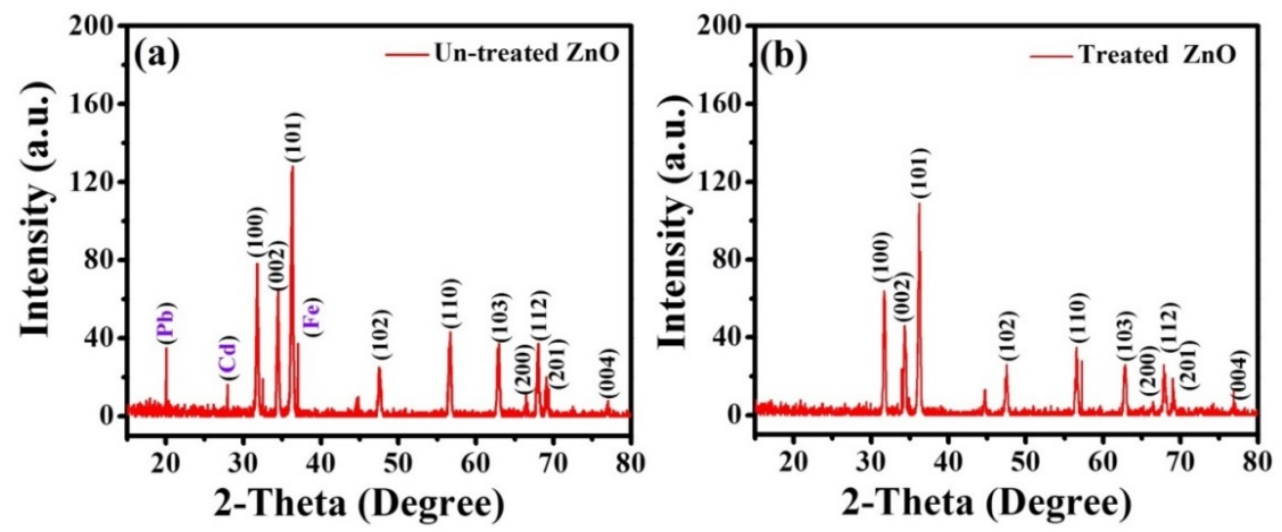

Fig. 3. XRD patterns of an un-treated (a) and (b) treated $\mathrm{ZnO}$ powders.

Elemental Analysis by FAAS. For further confirmation of leaching effect, un-treated and treated $\mathrm{ZnO}$ samples were investigated by flammable atomic absorption spectroscopy (FAAS) for three elements $(\mathrm{Fe}, \mathrm{Cd} \& \mathrm{~Pb})$. The results indicate that treated $\mathrm{ZnO}$ powder contains lower concentrations of impurities (Fe: $129 \mathrm{mg} \mathrm{kg}^{-1}, \mathrm{Cd}: 19.7 \mathrm{mg} \mathrm{kg}^{-1}$ and $\mathrm{Pb}: 141 \mathrm{mg} \mathrm{kg}^{-1}$ ) than that of untreated $\mathrm{ZnO}$ powder (Fe: $515 \mathrm{mg} \mathrm{kg}^{-1}, \mathrm{Cd}: 308 \mathrm{mg} \mathrm{kg}^{-1}$ and $\mathrm{Pb}: 1449 \mathrm{mg} \mathrm{kg}^{-1}$ ), shown in Table 3. Interestingly, the reduction in $\mathrm{Pb}$ ion concentration was observed as $1308 \mathrm{mg} \mathrm{kg}^{-1}$ which is higher than that of $\mathrm{Fe}$ and $\mathrm{Cd}$ i.e. $288.3 \mathrm{mg} \mathrm{kg}^{-1}$ and $386 \mathrm{mg} \mathrm{kg}^{-1}$, respectively. The differences in values suggest that the ammonium carbonate solution is adsorbent for the $\mathrm{Pb}$-adsorption because $\mathrm{Pb}$ ion is the harder Louise acid than other heavy metal ions [10].

Table 3. Chemical analysis of treated and un-treated $\mathrm{ZnO}$ based of FAAS analysis.

\begin{tabular}{|l|c|c|c|}
\hline \multicolumn{1}{|c|}{ Elements } & Pb & Cd & Fe \\
\hline Un-treated $\mathrm{ZnO}[\mathrm{mg} / \mathrm{kg}]$ & 1449 & 308 & 515 \\
\hline Treated $\mathrm{ZnO}[\mathrm{mg} / \mathrm{kg}]$ & 141 & 19.7 & 129 \\
\hline
\end{tabular}

\section{Conclusions}

The present research work examined the effect of ammonium carbonate solution on the removal of heavy metals from low grade commercial $\mathrm{ZnO}$ powder at laboratory scale. The absorbing capacity of ammonium carbonate solution was found up to $1308 \mathrm{mg} \cdot \mathrm{kg}^{-1}$ for the removal of $\mathrm{Pb}$ in low grade commercial $\mathrm{ZnO}$ powder that was characterized by FAAS. The removal process was also noted to be effective for other heavy metals like $\mathrm{Fe}$ and $\mathrm{Cd}$, which showed reduction capacity of $288.3 \mathrm{mg} \cdot \mathrm{kg}^{-1}$ and $386 \mathrm{mg} \cdot \mathrm{kg}^{-1}$, respectively. In addition, removal of heavy metals was also confirmed by using SEM, XRD and EDS techniques. These results are promising and confirm the advantage of the approach adopted presently. Therefore, such ammonium carbonate solution can be a suitable material for leaching of the low grade commercial $\mathrm{ZnO}$ powder for removal of heavy metal ion since the method is simple, fast, effective and economically viable for large production of $\mathrm{ZnO}$.

\section{Acknowledgements}

This work was supported in part by University of Karachi, NED University of Engineering \& Technology, Karachi and Pakistan Council of Scientific \& Industrial Research (PCSIR) Laboratories, Karachi, Pakistan. 


\section{References}

[1] Y. Zhang, T.R Nayak, H. Hong, W. Cai, Biomedical applications of zinc oxide nanomaterials, Curr. Molec. Med., 13 (2013) 1633-1645.

[2] A. Shaporev, V. Ivanov, A. Baranchikov, O. Polezhaeva, Y.D. Tret'yakov, ZnO formation under hydrothermal conditions from zinc hydroxide compounds with various chemical histories, Russian J. Inorg. Chem., 52 (2007) 1811-1816.

[3] A. Bakin, A.C. Mofor, A. El-Shaer, A. Waag, Vapour phase transport growth of ZnO layers and nanostructures, Superlattic. Microstruct., 42 (2007) 33-39.

[4] M. Ai-yuan, P. Jin-hui, Z. Li-bo, S. Li, Y. Kun, Z. Xue-mei, Leaching zn from the low-grade zinc oxide ore in $\mathrm{NH}_{3}-\mathrm{H}_{3} \mathrm{C}_{6} \mathrm{H}_{5} \mathrm{O}_{7}-\mathrm{H}_{2} \mathrm{O}$ media, Brazi. J. Chem. Eng., 33 (2016) 907-917.

[5] S. Yanbo, T. Xin, Study of new process technology for low-grade refractory zinc oxide ore, Procedi. Environ. Sci., 31 (2016) 195-203.

[6] S.J. Ma, J.L. Yang, G.F. Wang, W. Mo, X.J. Su, Alkaline Leaching of Low Grade Complex Zinc Oxide Ore, in: Advanced Materials Research, vol. 158, Trans. Tech. Publ., 2011, pp. 12-17.

[7] M.Y. Khan, R. Ahmad, G.H. Lee, E.-K. Suh, Y.-B. Hahn, Effect of annealing atmosphere on the optical and electrical properties of Al-doped $\mathrm{ZnO}$ films and $\mathrm{ZnO}$ nanorods grown by solution process, Sci. Advan. Mater., 8 (2016) 1523-1529.

[8] M. Vaseem, K.-M. Lee, J.-K. Shin, Y.-B. Hahn, Synthesis of ZnO nanoparticles and their inkjetting behavior, J. Nanosci. Nanotechnol., 12 (2012) 2380-2386.

[9] R.-X. Wang, M.-T. Tang, S.-H. Yang, W.-H. Zhagn, C.-B. Tang, J. He, J.-G. Yang, Leaching kinetics of low grade zinc oxide ore in $\mathrm{NH}_{3}-\mathrm{NH}_{4} \mathrm{Cl}-\mathrm{H}_{2} \mathrm{O}$ system, J. Cent. South Univer. Technol., 15 (2008) 679-683.

[10] N. Moayyeri, K. Saeb, E. Biazar, Removal of heavy metals (lead, cadmium, zinc, nickel and iron) from water by bio-ceramic absorbers of hydroxy-apatite microparticles, International Journal of Mari. Sci. Eng., 3 (2013) 13-16. 